\title{
Inclusion Exclusion Criterion Test
}

National Cancer Institute

\section{Source}

National Cancer Institute. Inclusion Exclusion Criterion Test. NCI Thesaurus. Code C83147.

A character or string that represents the full name of the inclusion exclusion criterion assessment. 